\title{
Supraspinal Brain-Derived Neurotrophic Factor Signaling: A Novel Mechanism for Descending Pain Facilitation
}

\author{
Wei Guo, ${ }^{\star}$ Meredith T. Robbins, ${ }^{\star}$ Feng Wei, ${ }^{\star}$ Shiping Zou, Ronald Dubner, and Ke Ren \\ Department of Biomedical Sciences, Program in Neuroscience, Dental School, University of Maryland, Baltimore, Maryland 21201
}

\begin{abstract}
In the adult mammalian brain, brain-derived neurotrophic factor (BDNF) is critically involved in long-term synaptic plasticity. Here, we show that supraspinal BDNF-tyrosine kinase receptor B (TrkB) signaling contributes to pain facilitation. We show that BDNF-containing neurons in the periaqueductal gray (PAG), the central structure for pain modulation, project to and release BDNF in the rostral ventromedial medulla (RVM), a relay between the PAG and spinal cord. BDNF in PAG and TrkB phosphorylation in RVM neurons are upregulated after inflammation. Intra-RVM sequestration of BDNF and knockdown of TrkB by RNA interference attenuate inflammatory pain. Microinjection of BDNF (10-100 fmol) into the RVM facilitates nociception, which is dependent on NMDA receptors (NMDARs). In vitro studies with RVM slices show that BDNF induces tyrosine phosphorylation of the NMDAR NR2A subunit in RVM via a signal transduction cascade involving $\mathrm{IP}_{3}, \mathrm{PKC}$, and Src. The supraspinal BDNF-TrkB signaling represents a previously unknown mechanism underlying the development of persistent pain. Our findings also caution that application of BDNF for recovery from CNS disorders could lead to undesirable central pain.
\end{abstract}

Key words: neurotrophin; TrkB; neuronal plasticity; periaqueductal gray; medulla; pain

\section{Introduction}

Recent evidence indicates that brain-derived neurotrophic factor (BDNF), a member of the neurotrophin family that is essential for neuronal survival during development, is widely expressed throughout the nervous system (Conner et al., 1997; Yan et al., 1997a) and contributes to synaptic plasticity in the adult mammalian brain (Schinder and Poo, 2000). The effects of BDNF are mediated through its binding to the tyrosine kinase receptor $\mathrm{B}$ (TrkB) and subsequent activation of downstream signaling pathways (Huang and Reichardt, 2003). The BDNF-TrkB signaling has been shown to play a critical role in activity-dependent synaptic plasticity underlying learning and memory (Schinder and Poo, 2000; Lu, 2003).

Brainstem descending pathways linking the periaqueductal gray (PAG), the rostral ventromedial medulla (RVM), and the spinal cord constitute a major mechanism in the modulation of pain transmission (Fields and Basbaum, 1999) (supplemental Fig. 1, available at www.jneurosci.org as supplemental material). Recent studies indicate that persistent pain after tissue or nerve injury is linked to an enhanced activation of descending modulatory circuits. An increased net descending facilitatory drive leads to an amplification and spread of the pain (for review, see Urban and Gebhart, 1999; Porreca et al., 2002; Ren and Dubner, 2002; Vanegas and Schaible, 2004). The increased excitability in

\footnotetext{
Received Aug. 31, 2005; revised Nov. 6, 2005; accepted Nov. 6, 2005.

This work was supported by National Institutes of Health Grants DA10275 and DE11964. We thank E. B. Wade for technical assistance.

*W.G., M.T.R., and F.W. contributed equally to this work.

Correspondence should be addressed to Dr. Ke Ren, Department of Biomedical Sciences, Room 5A26, 666 West Baltimore Street, Baltimore, MD 21201-1510. E-mail: kren@umaryland.edu.

DOI:10.1523/JNEUROSCI.3686-05.2006

Copyright $\odot 2006$ Society for Neuroscience $\quad$ 0270-6474/06/260126-12\$15.00/0
}

the descending circuitry after injury likely reflects long-lasting changes in synaptic efficacy, similar to that seen in hippocampal synapses that are involved in learning and memory. However, the cellular mechanisms underlying injury-induced synaptic plasticity in pain modulatory circuitry are poorly understood.

Studies have shown high levels of BDNF mRNAs and proteins within the PAG (Ceccatelli et al., 1991; Conner et al., 1997). Abundant TrkB mRNAs and proteins are observed in RVM neurons projecting to the spinal dorsal horn (Yan et al., 1997b; King et al., 1999). At the spinal level, BDNF is distributed in primary sensory neurons in the dorsal root ganglion (DiStefano et al., 1992; Mannion et al., 1999) and is involved in central sensitization in the spinal dorsal horn (Mannion et al., 1999; Kerr et al., 1999; Pezet et al., 2002a; Malcangio and Lessmann, 2003). Given the matching distribution of the BDNF-TrkB system in the PAGRVM circuitry, we hypothesize that supraspinal BDNF-TrkB receptor signaling plays an important role in the development of persistent pain after injury. Here, we show for the first time that BDNF-containing neurons in the PAG project to and release BDNF in the RVM and peripheral inflammation induces an enhanced expression of BDNF in PAG and TrkB receptor phosphorylation in RVM neurons. Sequestration of endogenous BDNF and knockdown of TrkB by RNA interference (RNAi) in the RVM attenuates inflammatory hyperalgesia. Microinjection of BDNF into the RVM produces descending pain facilitation, which is dependent on the activation of NMDA receptors (NMDARs). In vitro studies with RVM slices show that BDNF induces tyrosine phosphorylation of the NR2A subunit of the NMDAR through a signal transduction cascade that involves $\mathrm{IP}_{3}$, $\mathrm{PKC}$, and Src family tyrosine kinase. The BDNF-TrkB signaling in the supraspinal circuitry represents a previously unknown 
mechanism underlying the development and maintenance of plasticity and persistent pain.

\section{Materials and Methods}

Animals. Adult male Sprague Dawley rats weighing 250-300 g (Harlan, Indianapolis, IN) were used in all experiments. Rats were on a $12 \mathrm{~h}$ light/dark cycle and received food and water ad libitum. The experiments were approved by the Institutional Animal Care and Use Committee of the University of Maryland Dental School.

Hindpaw inflammation. A unilateral hindpaw inflammation was produced by a subcutaneous injection of complete Freund's adjuvant (CFA) (0.05 ml; Sigma, St. Louis, MO) suspended in an oil/saline (1:1) emulsion into the plantar surface of one hindpaw. The CFA injection produced an intense tissue inflammation of the hindpaw characterized by erythema, edema, and hyperalgesia (Iadarola et al., 1988). The CFA-treated animals groom normally and display normal locomotor activity. They maintain their weight, explore their environment, and interact with their cage mates. Saline $(0.05 \mathrm{ml} ; 0.9 \%)$ was used as a control for CFA.

Intra-RVM microinjections. Animals were anesthetized with 2-3\% isoflurane in a gas mixture of $30 \% \mathrm{O}_{2}$ balanced with nitrogen and placed in a Kopf stereotaxic instrument (Kopf Instruments, Tujunga, CA). A midline incision was made after infiltration of lidocaine (2\%) into the skin. A midline opening was made in the skull with a dental drill to insert a microinjection needle into the target site. The coordinates for the nucleus raphe magnus (NRM), the major structure of RVM, were as follows: $10.5 \mathrm{~mm}$ caudal to bregma, midline and $9.0 \mathrm{~mm}$ ventral to the surface of the cerebellum (Paxinos and Watson, 2005). To avoid penetration of the transverse sinus, the incisor bar was set at $4.7 \mathrm{~mm}$ below the horizontal plane passing through the interaural line. Animals were subsequently maintained at $\sim 1 \%$ halothane. Microinjections were performed by delivering drug solutions slowly over a $10 \mathrm{~min}$ period using a $500 \mathrm{nl}$ Hamilton syringe with a 32 gauge needle. The needle was withdrawn 5 min after the completion of the injection and the incision sutured. Different groups of animals were subjected to injection of human recombinant BDNF (Amgen, Thousand Oaks, CA), human recombinant TrkB-IgG (R \& D Systems, Minneapolis, MN), or rabbit anti-BDNF antisera (Chemicon, Temecula, CA). The control rats underwent identical procedures with injection of the same volume $(500 \mathrm{nl})$ of the vehicles. All wound margins were covered with a local anesthetic ointment $(\mathrm{Nu}-$ percainal; Rugby Laboratories, Norcross, GA). The animals recovered from anesthesia $\sim 5-10 \mathrm{~min}$ after microinjection. For retrograde tracing, cholera toxin subunit B (CTB) (1\%, $250 \mathrm{nl}$; List Biologic, Campbell, CA) was microinjected into the NRM. After $4 \mathrm{~d}$ of survival, the animals were deeply anesthetized with sodium pentobarbital (100 mg/kg, i.p.) and perfused through the ascending aorta with $200 \mathrm{ml}$ of saline followed by $500 \mathrm{ml}$ of $4 \%$ paraformaldehyde in $0.1 \mathrm{M}$ phosphate buffer.

Intra-PAG electrical stimulation. Animals were anesthetized with isoflurane and mounted in a stereotaxic apparatus as described above. The stimulation site in the ventrolateral PAG was located stereotaxically (7.5-8.8 mm caudal to bregma, $0.4 \mathrm{~mm}$ lateral to the midline, and $4.5-$ $4.8 \mathrm{~mm}$ deep from the surface of the cerebral cortex), and a monopolar electrode consisting of Teflon-insulated stainless steel wire $(0.1 \mathrm{~mm})$ exposed only at the cut tip was introduced. The indifferent electrode was attached to the neck muscles. The PAG was stimulated with 60 trains (square pulses of $0.5 \mathrm{~ms}, 67 \mathrm{~Hz}, 0.25 \mathrm{~mA}$ ) for a total of $10 \mathrm{~min}$ ( $1 \mathrm{~s}$ on and $9 \mathrm{~s}$ off). At $30 \mathrm{~min}$ after stimulation, the animals were deeply anesthetized with sodium pentobarbital (100 mg/kg, i.p.); the RVM was rapidly dissected and stored at $-80^{\circ} \mathrm{C}$ for immunoblot analysis. The medulla was also removed for double immunostaining after animals were perfused with $4 \%$ paraformaldehyde.

Targeted small interfering RNA transfer by electroporation. The method for regional gene transfer in vivo with electroporation (Wei et al., 2003) was used for TrkB small interfering RNA (siRNA) transfer in the RVM. The surgical procedure was the same as that for intra-RVM microinjections. The siRNAs, including TrkB siRNA (70 and $280 \mathrm{ng} / 500 \mathrm{nl}$ ) and the control siRNA (70 ng), were injected into the RVM. All siRNAs were purchased from Santa Cruz Biotechnology (Santa Cruz, CA). After the completion of the injection volume, the injection needle was left in place for at least $15 \mathrm{~min}$ before being slowly withdrawn. A pair of Teflon- coated silver positive and negative electrodes were placed around the microinjection sites rostrocaudally. The tip of the wires was naked, and the bare length was $2 \mathrm{~mm}$. For transfer of negatively charged siRNA into RVM neurons, seven square wave electric pulses $(50 \mathrm{~ms}, 40 \mathrm{~V}, 1 \mathrm{~Hz}$; model 2100; A-M Systems, Carlsborg, WA) were delivered. The wound was closed and animals returned to their cages after they recovered from anesthesia. In some experiments, control siRNA conjugated with fluorescein (70 ng) was injected to the RVM and then followed by focal electroporation.

Behavioral testing. The paw withdrawal latency was determined by a method described previously in detail (Hargreaves et al., 1988). The rats were placed under an inverted clear plastic cage on an elevated glass surface and allowed to acclimatize for 15-30 min. A radiant heat stimulus was applied from underneath the glass floor with a high-intensity projector lamp bulb (Osram 58-8007, 8 V, 50 W; Osram, Berlin, Germany). The heat stimulus was focused on the plantar surface of each hindpaw, and the paw withdrawal latency to the nearest $0.1 \mathrm{~s}$ was determined using an electronic clock circuit. Bulb voltage was adjusted to derive an average baseline withdrawal latency of $\sim 10.0 \mathrm{~s}$ in naive animals. A $20 \mathrm{~s}$ cutoff was used to prevent tissue damage. Before the microinjection of drugs, three measures (each separated by a 5 min interval) were obtained for each hindpaw, and the mean was designated the predrug latency. Paw withdrawal latencies were measured at different times after microinjection.

Immunohistochemistry. At different time points after hindpaw inflammation, rats were deeply anesthetized with pentobarbital and perfused transcardially with $200 \mathrm{ml}$ of saline followed by $500 \mathrm{ml}$ of cold $\left(4^{\circ} \mathrm{C}\right) 0.1$ м phosphate buffer containing $4 \%$ paraformaldehyde. The brainstem was removed, immersed in the same fixative overnight at $4^{\circ} \mathrm{C}$, and transferred to $30 \%$ sucrose $(\mathrm{w} / \mathrm{v})$ in phosphate buffer for several days for cryoprotection. Thirty-micrometer-thick coronal sections of the brainstem were cut with a cryostat at $-20^{\circ} \mathrm{C}$. Free-floating tissue sections, including the PAG and RVM, were incubated with sheep anti-BDNF (1:1000; Chemicon) or rabbit anti-TrkB (1:5000; Chemicon) antibodies overnight, respectively. For colocalization of TrkB with NR2A, the RVM sections were incubated in mixed rabbit anti-TrkB (1:1000) and mouse anti-NR2A (1:1000; Chemicon) antibodies. The sections were then incubated with biotinylated donkey anti-sheep or donkey anti-rabbit IgG (Jackson ImmunoResearch, West Grove, PA) or goat anti-rabbit or goat anti-mouse IgG (Vector Laboratories, Burlingame, CA) followed by streptavidin-conjugated Alexa Fluor 488 or 568 (1:600; Invitrogen, Eugene, OR). After washes in PBS, sections were mounted on gelatin-coated slides and coverslipped with Vectashield (Vector Laboratories). Control sections were processed with the same method except that the primary antisera was omitted or adsorbed by respective antigens.

For the combination of retrograde tracing with immunohistochemistry, the sections, including the PAG of normal animals, were incubated in mixed goat anti-CTB antibody (1:10,000; List Biologic) and sheep antiBDNF (1:500; Chemicon) antibody in PBS overnight and then incubated in donkey anti-goat IgG conjugated with Alexa Fluor 568 (1:600) and donkey anti-sheep IgG conjugated with Alexa Fluor 488 (1:600; Invitrogen).

Tyramide signal amplification was used for double immunostaining to identify phosphorylation of TrkB as described previously (Guo et al., 2004). Antibody Tyr490 (Cell Signaling Technology, Beverly, MA), a rabbit anti-phospho-TrkA/B antiserum directed against a synthetic phospho-peptide corresponding to residues 485-493 of human TrkA, was used to detect the phosphorylated form of the TrkA/B receptor. After incubation with the first primary antibody, rabbit Tyr490 (10,000), sections were reacted with biotinylated donkey anti-rabbit antibody (1:600; Jackson ImmunoResearch) followed by incubation with Streptavidinconjugated peroxidase. After the application of cyanine 3-tyramide (PerkinElmer, Boston, MA), sections were incubated in $4 \mathrm{~m}$ urea (carbamide; in distilled water; Sigma) for $15 \mathrm{~min}$. The treatment with the denaturing reagent removes the primary-secondary antibody complex, whereas the tyramide fluorescein marker deposited on the tissue remains. The sections were then incubated with the second primary antibody, rabbit anti-TrkB (1:1000; Upstate Biotechnology, Charlottesville, VA) and visualized by goat anti-rabbit IgG conjugated to Alexa Fluor 488 (1:600; Invitrogen). The specificity of the double labeling with Tyr490 
was verified with mouse anti-TrkB (1:600; Neuromics, Bloomington, $\mathrm{MN})$ or goat anti-TrkA (1:600; R \& D Systems). To control for cross reactions between the two primary antibodies, some sections were processed as above except that the second primary antibody was omitted. Images were collected sequentially on the Zeiss (Thornwood, NY) 510 MATA laser-scanning confocal microscope.

The fluorescent immunostaining for BDNF in ventrolateral PAG neurons was quantified by using NIH Image (Scion Image; Scion, Frederick, $\mathrm{MD}$ ) to obtain measurements of the relative fluorescence intensity in the whole-cell body area compared with that in the adjacent background (Wei et al., 2002). All data were shown as a ratio of the staining intensities between the cytosolic area and the surrounding background of each neuron. Only neurons with sharp boundaries and a well defined nucleus were considered. At least 10 neurons were measured from three different sections in each animal and then the data were averaged.

Brainstem/RVM slice. Normal adult male Sprague Dawley rats weighing 150-200 g (Harlan) were anesthetized with 2\% halothane and decapitated. The brainstem was removed quickly and kept in cold artificial CSF (aCSF) consisting of the following (in $\mathrm{mm}$ ): $124 \mathrm{NaCl}, 4.4 \mathrm{KCl}, 25$ $\mathrm{NaHCO}_{3}, 2.0 \mathrm{CaCl}_{2}, 1.0 \mathrm{MgSO}_{4}, 1.0 \mathrm{NaH}_{2} \mathrm{PO}_{4}, 10$ D-glucose, $\mathrm{pH} 7.4$, and bubbled with $95 \% \mathrm{O}_{2}$ and $5 \% \mathrm{CO}_{2}$. Transverse brainstem slices at the RVM level $\left(0.6 \mathrm{~mm}\right.$ thick) were cut at $4^{\circ} \mathrm{C}$ using a vibratome and immersed in chambers perfused at $5 \mathrm{ml} / \mathrm{min}$ with oxygenated aCSF. The slices were treated at room temperature with different drugs (see Results) to test their effect on receptor phosphorylation. At the conclusion of pharmacological treatment, the RVM tissues were punched out (Guan et al., 2003) and homogenized to extract proteins for immunoprecipitation and Western blot analysis.

Western blot and immunoprecipitation. Naive and treated rats were anesthetized with $2 \%$ halothane and decapitated. The RVM tissues were removed (Guan et al., 2003) and homogenized in solubilization buffer (50 mm Tris-HCl, pH 8.0, 150 mm NaCl, 1 mm EDTA, 1\% Triton X-100, $0.5 \%$ deoxycholic acid, $0.1 \%$ SDS, $1 \mathrm{~mm} \mathrm{Na} 3 \mathrm{VO} 4,1 \mathrm{U} / \mathrm{ml}$ aprotinin, 2 $\mu \mathrm{g} / \mathrm{ml}$ leupetin, $2 \mu \mathrm{g} / \mathrm{ml}$ pepstatin A). The homogenate was centrifuged at $20,200 \times g$ for $10 \mathrm{~min}$ at $4^{\circ} \mathrm{C}$, and the supernatant was removed. The protein concentration was determined. Each sample contained proteins from one animal.

For Western blot analysis, the proteins $(50 \mu \mathrm{g})$ were separated on a 7.5\% SDS-PAGE gel and blotted to a nitrocellulose membrane (Amersham Biosciences, Arlington Heights, IL). The blot was incubated with the respective antibody overnight at $4^{\circ} \mathrm{C}$. The membrane was washed with Tris-buffered saline and incubated for $1 \mathrm{~h}$ with anti-goat IgG horseradish peroxidase (HRP) (1:3000; Santa Cruz Biotechnology) in 5\% milk. The immunoreactivity was detected using enhanced chemiluminescence (ECL) (Amersham Biosciences). The loading and blotting of equal amounts of protein were verified by reprobing the membrane with anti $\beta$-actin antiserum (Sigma).

For immunoprecipitation, the samples were incubated with the same amount of respective antiserum (4 mg) overnight and then with protein A/G-agarose beads (Santa Cruz Biotechnology). SDS sample buffer $(0.05$ $\mathrm{ml}$ ) was added to elute proteins from the protein A/G beads. The eluant was separated on SDS-polyacrylamide gel $(7.5 \%)$ and transferred to a nitrocellulose membrane. To determine the level of tyrosine phosphorylation, the membranes were blocked and incubated with antiphosphotyrosine 4G-10 (1:1000; Upstate Biotechnology) and further washed and incubated with anti-mouse IgG HRP (1:3000), and ECL was performed. The membranes were then stripped and reprobed with antiTrkB antiserum or anti-NR2A antiserum (1:1000) to verify the amount of immunoprecipitated proteins.

The ECL-exposed films were digitized, and densitometric quantification of immunoreactive bands was performed using U-SCAN-IT gel (version 4.3; Silk Scientific, Orem, UT). The relative tyrosinephosphorylated protein levels were obtained by comparing the antiphosphotyrosine immunoblot against the corresponding TrkB or NR2A subunit immunoblot from the same membrane, and the deduced ratios were further normalized to that of the control rats. Data are illustrated as percentage of the controls. Raw data (ratio of the 4G-10 band over TrkB or NR2A band) were used for statistical comparisons. ANOVA and the unpaired two-tailed $t$ test were used to determine the significant differ- ences between sample groups. $p<0.05$ was considered significant in all cases.

BDNF enzyme-linked immunosorbant assay. Naive and CFA-treated rats were killed by overdose with $2 \%$ halothane. The RVM tissues were weighed and homogenized in cold extraction buffer $(50 \mathrm{~mm}$ Tris- $\mathrm{HCl}$, pH 8.0, 150 mм NaCl, 1 mм EDTA, 1\% Triton X-100, 0.5\% deoxycholic acid, $0.1 \%$ SDS, $1 \mathrm{U} / \mathrm{ml}$ aprotinin, $2 \mu \mathrm{g} / \mathrm{ml}$ leupetin, $2 \mu \mathrm{g} / \mathrm{ml}$ pepstatin A). The BDNF levels (pg/mg protein) were determined by using the Chemikine BDNF assay kits (Chemicon) following the protocol of the manufacturer.

Histological reconstruction. The location of microinjection in the RVM and electrical stimulation in the PAG were determined by visualization of Nissl-stained tissue under a microscope. Rats with misplaced microinjection or stimulation were excluded from the data analysis.

Data analysis. Results were expressed as mean \pm SEM. Statistical comparisons included one- or two-way ANOVA with the post hoc Scheffé's $F$ test in immunocytochemical experiments or the Student-NewmanKeuls test in behavioral experiments (ANOVA with repeated measures). In all cases, $p<0.05$ was considered statistically significant.

\section{Results \\ Inflammation-induced increase in BDNF expression in PAG neurons}

Previous studies have characterized the distribution of BDNFcontaining neurons in the PAG of adult rats (Ceccatelli et al., 1991; Conner et al., 1997). However, it is unclear whether BDNFcontaining PAG neurons are involved in the response to injury. Using a rat model of inflammation and hyperalgesia, we first examined the effect of hindpaw inflammation on BDNF expression in the PAG. An inflammatory agent, CFA, was injected subcutaneously into one hindpaw to produce an intense tissue inflammation characterized by erythema, edema, and pain (Iadarola et al., 1988). Immunostaining showed that BDNFlabeled neurons were widely present in all portions of the PAG, including the ventrolateral portion (Fig. $1 A, B$ ). Compared with the control rats, substantial increases in BDNF-like immunoreactivity in ventrolateral PAG neurons were observed at 1 and $3 \mathrm{~d}$ after inflammation. Quantitative densitometric analysis of BDNF-like immunoreactivity showed a significant upregulation by approximately threefold at $1 \mathrm{~d}$ and fourfold at $3 \mathrm{~d}$ after injury (Fig. $1 C)(n=4-5$ each group; $p<0.01)$. Western blot analysis identified a $14 \mathrm{kDa}$ band that corresponded to the molecular weight of the mature BDNF (Fig. 1D), which showed similar levels of upregulation after inflammation (Fig. $1 D$ ). These results suggest that changes in BDNF expression occur in PAG neurons after peripheral injury.

\section{BDNF-containing neurons in the PAG project to the RVM}

The descending input from PAG is relayed to the RVM, a pivotal structure in descending pain modulation (Fields and Basbaum 1999). We asked whether BDNF-containing neurons in the PAG project to RVM. A retrograde tracer cholera toxin subunit B (1\%; $500 \mathrm{nl}$ ) was microinjected into the RVM. As shown in Figure $1 E$, the injection site was centered in the NRM. A large number of CTB-labeled neurons were found in the ventrolateral region of the PAG (Fig. $1 F$ ), consistent with a previous report (Van Bockstaele et al., 1991). Double immunostaining further showed that a population of retrogradely labeled neurons in the ventrolateral PAG was immunoreactive for BDNF (Fig. $1 G-L$ ). We found that $63 \pm 4 \%$ of CTB-labeled neurons $(18 \pm 0.9$ per section; $n=4)$ in the unilateral ventrolateral PAG expressed BDNF (11.3 \pm 0.7 per section). A smaller proportion of PAG-RVM projection neurons in the lateral PAG were labeled for BDNF (41 $\pm 6 \%$ ). Thus, a major population of RVM-projecting PAG neurons express BDNF. 

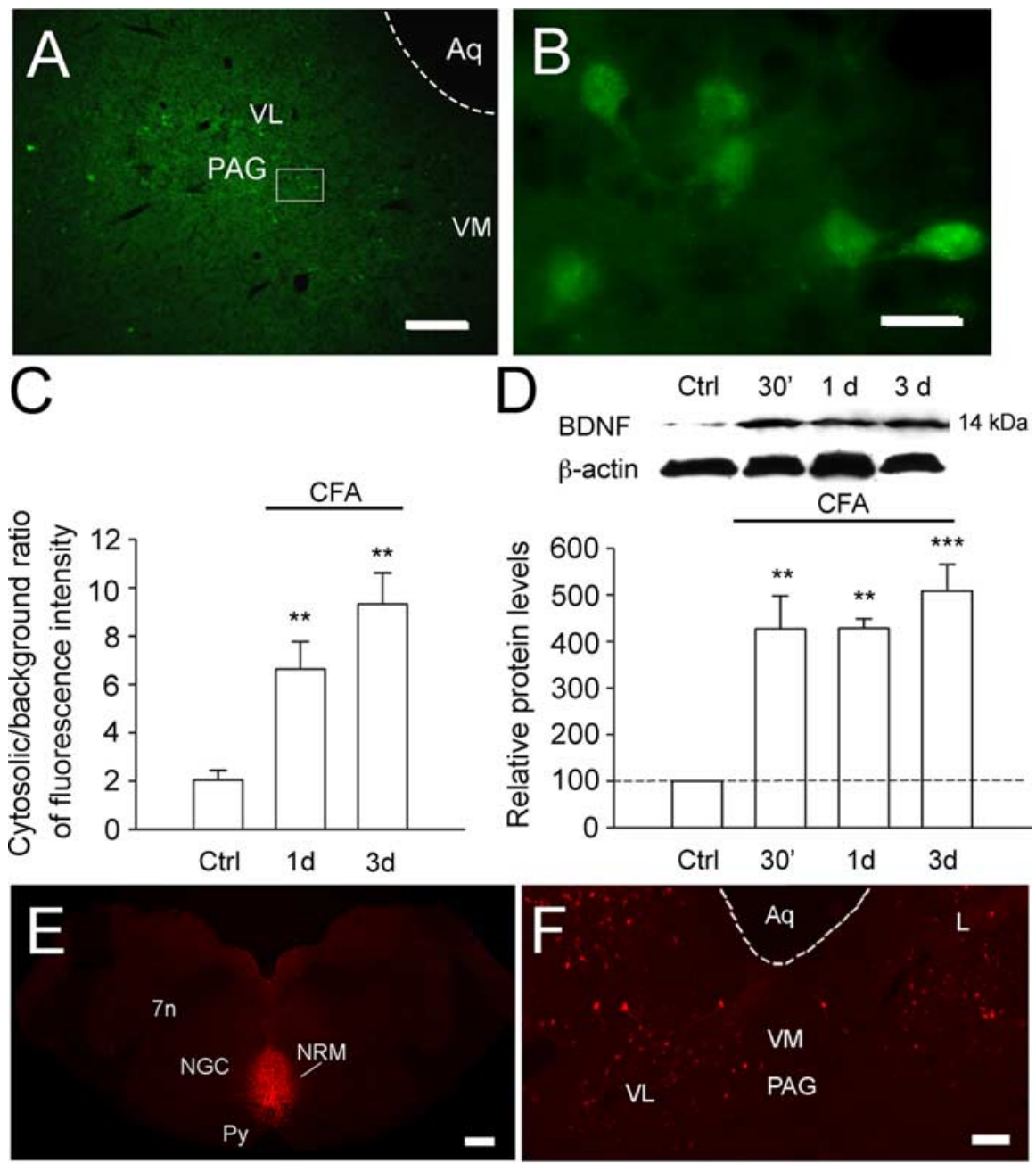

CTB
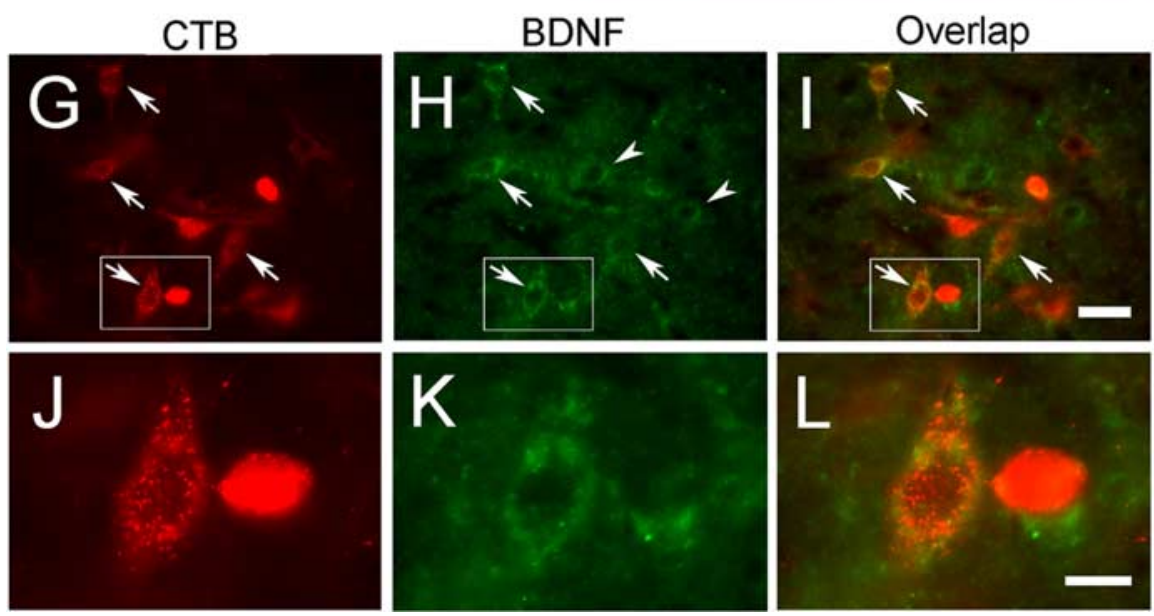

Figure 1. Inflammation-induced upregulation of BDNF in the PAG and projection of PAG BDNF-containing neurons to the RVM. $\boldsymbol{A}, \boldsymbol{B}$, The distribution of BDNF-containing neurons in the ventrolateral PAG. The inset in $\boldsymbol{A}$ is enlarged in $\boldsymbol{B}$ to show BDNF-labeled neurons. $C$, Summary of the BDNF-like immunoreactivity in ventrolateral PAG neurons. There are significant increases in the relative intensity of neuronal BDNF staining at 1 and $3 \mathrm{~d}$ after CFA, compared with the control ( $p<0.01 ; n=4-5$ per group). $\boldsymbol{D}$, Western blot shows the time-dependent increase of BDNF expression in the PAG after inflammation. The top blots show examples of the immunoreactive bands against anti-BDNF. The bottom blots show immunobands against $\beta$-actin after stripping and reprobing the same membrane. The bottom bar graphs in $\boldsymbol{D}$ show the mean levels of BDNF normalized to $\beta$-actin. The relative BDNF levels (mean \pm SEM) after inflammation are expressed as a percentage of the controls. Asterisks indicate significant differences $\left({ }^{* *} p<0.01 ;{ }^{* * *} p<0.001\right)$ from the control. $n=4$ per time point. The dashed line indicates the control level. $\boldsymbol{E}$, CTB immunostaining shows an example of the microinjection site of the tracer in the RVM, centered in the NRM. $\boldsymbol{F}$, CTB-labeled neurons in the ventrolateral PAG, indicating PAG-RVM projection. $G-L$, Double immunostaining of PAG neurons ( $I$, $L$, yelloworange). Arrows in $\boldsymbol{G} \boldsymbol{I}$ indicate (TB-labeled neurons ( $\boldsymbol{G}$, red) that are also immunoreactive to BDNF ( $\boldsymbol{H}$, green), indicating BDNFergic projection from PAG to RVM. Arrowheads in $H$ represent single-labeled BDNF-containing neurons without CTB staining.
Inflammation upregulates TrkB receptor function in the $R V M$

The presence of a PAG-RVM BDNFergic projection strongly suggests BDNF-TrkB signaling in RVM neurons. To examine the receptor mechanisms related to the increased BDNF expression, we studied the effect of inflammation on $\mathrm{TrkB}$ receptor expression in the RVM. Immunostaining showed expression of TrkB in RVM neurons (Fig. $2 A, B$ ). Western blots demonstrated a time-dependent upregulation of full-length TrkB but not truncated TrkB protein levels from $30 \mathrm{~min}$ to $3 \mathrm{~d}$ after inflammation (Fig. 2C) $(p<0.05$ compared with naive group; $n=4$ each time point).

BDNF binds TrkB receptors on neuronal membrane surfaces to form a ligandreceptor complex that initiates phosphorylation of $\operatorname{TrkB}$ on its tyrosine residues (Pezet et al., 2002a; Du et al., 2003). An increase in phosphorylated TrkB receptors in TrkB-labeled neurons can be used as a measure of increased activation of the receptor and provides evidence for the presynaptic release of BDNF (Pezet et al., 2002b; Du et al., 2003). We investigated the time course of phosphorylation of the TrkB receptor ( $\mathrm{pTrkB}$ ) in the $\mathrm{RVM}$ after tissue injury. Extracted proteins from RVM tissue were immunoprecipitated with anti-TrkB antibody and then immunoblotted against 4G-10, an antiphosphotyrosine antibody. Inflammation induced a prolonged increase in $\mathrm{pTrkB}$ in the RVM (Fig. $2 D)$ ( $n=4$ each time point; $p<0.05)$. Both TrkB and $\mathrm{pTrkB}$ levels returned to baseline levels at 7-14 d after inflammation (Fig. 2C,D).

\section{Electrical stimulation of the PAG induces TrkB phosphorylation in the RVM}

To identify activity-dependent release of BDNF into RVM and subsequent activation of TrkB receptors on RVM neurons, we next investigated TrkB receptor phosphorylation in RVM neurons after electrical stimulation of the ventrolateral PAG. A pattern of trains of burst stimulation (TBSs) has been shown to be effective in activating PAG neurons to release glutamate into the RVM (Cui et al., 1999) and

\footnotetext{
$\boldsymbol{J}, \boldsymbol{K}$, and $\boldsymbol{L}$ are enlarged from the insets in $\boldsymbol{G}, \boldsymbol{H}$, and $\boldsymbol{I}$, respectively, in which the neuron on the left is clearly double labeled and the neuron on the right is single labeled with CTB. Scale bars: $A, 0.2 \mathrm{~mm} ; \boldsymbol{B}, 0.02 \mathrm{~mm} ; \boldsymbol{E}, 0.5 \mathrm{~mm} ; \boldsymbol{F}, 0.1 \mathrm{~mm} ; \boldsymbol{G}-\boldsymbol{I}, 0.03$ $\mathrm{mm} ; J-L, 0.01 \mathrm{~mm}$. $7 \mathrm{n}$, Facial nerve; Aq, cerebral aqueduct; Ctrl, control; L, lateral PAG; NGC, gigantocellular reticular nucleus; Py, pyramidal tract; VM, ventromedial PAG; VL, ventrolateral PAG. Error bars represent SEM.
} 
C-fibers to release BDNF, substance $\mathrm{P}$, and glutamate into the spinal dorsal horn (Lever et al., 2001). We applied a similar TBS protocol (see Materials and Methods) to the ventrolateral PAG to activate PAG neurons in isoflurane anesthetized rats. The location of the TBS site in the PAG is shown in Figure 3A. We first assessed the pTrkB levels by Western blot after immunoprecipitation. Compared with the control group without stimulation, pTrkB levels in the RVM were significantly elevated at 30 min after electrical stimulation of the PAG (Fig. $3 B)(p<0.01 ; n=4$ /group). This result was confirmed with double immunostaining of Tyr490 (anti-phosphotyr490-TrkA/B antibody) with TrkB. Electrical stimulation of the PAG induced an increase in the numbers of pTrk (Tyr490)immunoreactive puncta in the cytoplasm and proximal dendrites of TrkB-labeled neurons in the RVM, compared with that of the sham group (Fig. 3C-J). The cytosolic/background ratios of fluorescence intensity were $2.38 \pm 0.18(n=16$ cells from 3 rats) after electrical stimulation of the PAG and $0.52 \pm 0.08(n=12$ cells from 3 rats) in the sham group ( $p<$ $0.001)$. There was no double immunostaining of Tyr490 with TrkA in the RVM after PAG stimulation (data not shown). These results suggest that activation of PAG induces functional release of BDNF into the RVM.

\section{Neutralizing endogenous BDNF in the RVM attenuates inflammatory hyperalgesia}

The finding that both BDNF in the PAG and its specific receptor TrkB in the RVM are dynamically upregulated after peripheral inflammation suggests that the enhanced BDNF-TrkB signaling in the RVM may contribute to neuronal plasticity in the descending pain modulatory pathways and underlie central mechanisms of persistent pain. Thus, inactivation of $\mathrm{BDNF} / \mathrm{TrkB}$ receptors in the RVM should affect behavioral hyperalgesia induced by inflammation. To block selective activation of TrkB receptors, we neutralized endogenous BDNF by microinjection of either anti-BDNF antibody or the TrkB-IgG fusion protein (TrkB-IgG or TrkB-Fc). TrkB-IgG is a compound of divalent homodimers containing the BDNFbinding domain of the TrkB receptor and acts as a false TrkB receptor to sequester endogenous BDNF. Single microinjection of anti-BDNF antisera or TrkB-IgG was targeted at the NRM, the center of the RVM (Fig. $4 A, B$ ). To examine the role of BDNF in the induction of inflammatory pain, we first injected the drugs at 30 min before the injection of CFA into the hindpaw. CFA produces a significant reduction in rat's paw withdrawal latency to a noxious thermal stimulus, indicating the development of hyperalgesia. Microinjection of anti-BDNF antibody $(25 \mathrm{ng} / 500 \mathrm{nl} ; n=$ 6 ) in the RVM induced complete inhibition of thermal hyperalgesia at $30 \mathrm{~min}$ after inflammation, and the inhibition persisted for at least $6 \mathrm{~h}$ when compared with the vehicle-injected group (Fig. $4 C)(p<0.01)$. Intra-RVM administration of TrkB-IgG (50 $\mathrm{ng} / 500 \mathrm{nl} ; n=6$ ) briefly but completely blocked behavioral hyperalgesia at $2 \mathrm{~h}$ after inflammation compared with the vehicleinjected rats $(n=5 ; p<0.001)$ (Fig. $4 C)$, suggesting that TrkBIgG was less effective than anti-BDNF in neutralizing BDNF in the RVM. There were no changes in thermal threshold to noxious heat on the contralateral hindpaw of the TrkB-IgG or anti-BDNF antisera-treated animals (data not shown). Thus, presequestration of the increased release of BDNF in the RVM dampened the development of hyperalgesia after inflammation.

To determine whether BDNF in the RVM plays a role in the maintenance of hyperalgesia, animals received a single microinjection of anti-BDNF antisera into the RVM at $3 \mathrm{~d}$ after inflammation. At this time point, the rats with an inflamed hindpaw showed intense hyperalgesia in the control group (Fig. 4D) $(n=$ 3). Microinjection of anti-BDNF antisera (25 ng/500 nl; $n=3$ ) into the RVM significantly attenuated thermal hyperalgesia for at least $6 \mathrm{~h}$ when compared with the vehicle treatment (Fig. 4D) $(p<0.01)$. There were no differences in the thermal response threshold of the noninflamed hindpaws between the antibody and vehicle-treated groups (data not shown). The basal paw withdrawal latency to noxious heat in non-CFA-treated animals was not affected by microinjection of TrkB-IgG $(n=6)$ or antiBDNF antisera $(n=6)$ into the RVM (data not shown). These results suggest that the enhanced levels of BDNF and activa- 

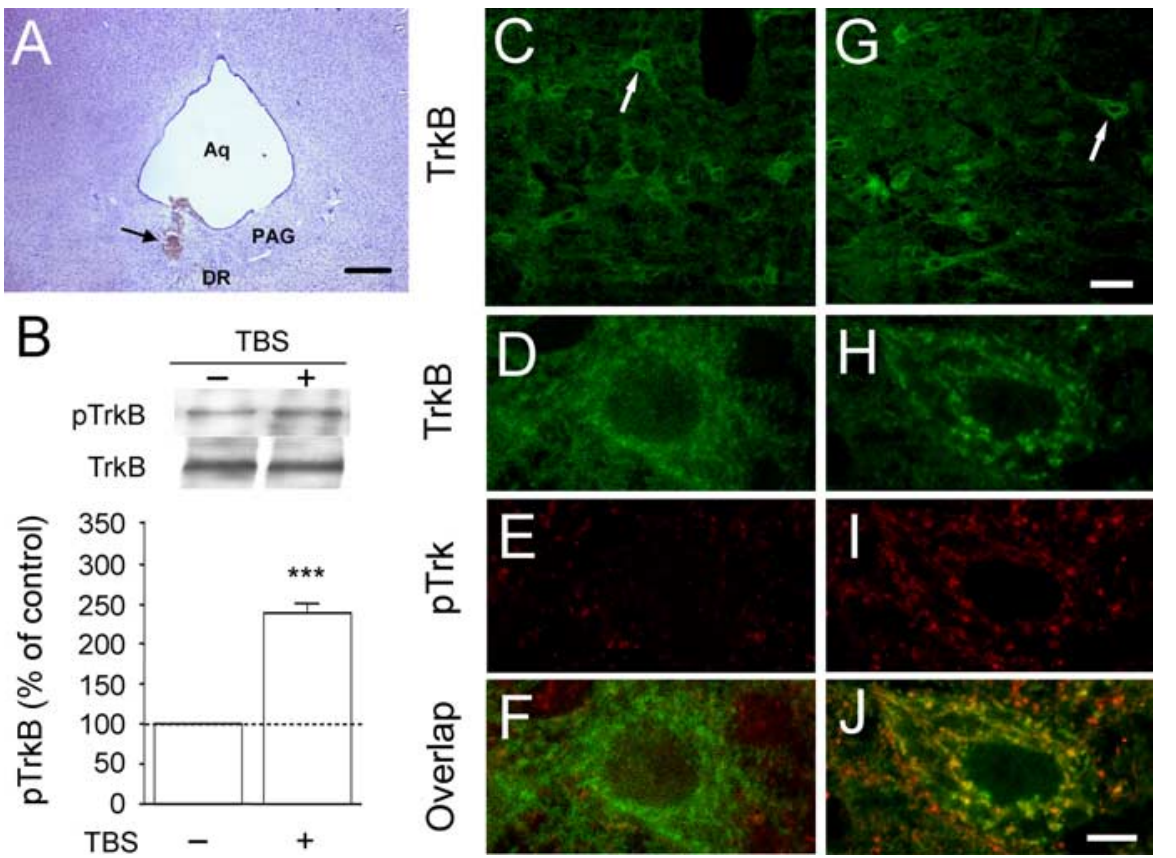

Figure 3. Electrical stimulation of the PAG-induced pTrkB in RVM. $\boldsymbol{A}$, The site of stimulation was in the ventrolateral PAG (arrow) (bregma, $-8.70 \mathrm{~mm}$ ). Aq, Cerebral aqueduct; DR, dorsal raphe nucleus. $\boldsymbol{B}$, TrkB phosphorylation in the RVM after PAG electrical stimulation. Compared with the sham control $(-)$, there was a significant increase $\left({ }^{* * *} p<0.01 ; n=4\right.$ per group) in pTrkB in the RVM at 30 min after electrical stimulation (TBS; +). C, TrkB-labeled neurons in the RVM of the sham control rats without TBS. G, TrkB-labeled neurons in the RVM after PAG TBS. $\boldsymbol{D}-\boldsymbol{F}$, Higher magnification of a neuron in $\boldsymbol{C}$ (arrow) illustrating double immunostaining for $\operatorname{TrkB}(\boldsymbol{D}$, green) and $\operatorname{Tr} 490(\boldsymbol{E}$, red). Very few double-labeled puncta were seen $(\boldsymbol{F}$, yellow) in this neuron. $\boldsymbol{H}-\boldsymbol{J}$, Higher magnification of a neuron in $\boldsymbol{G}$ (arrow) illustrating double immunostaining for TrkB ( $\boldsymbol{H}$, green) and Tyr490 (I, red). Note the appearance of double labeling ( $\boldsymbol{J}$, yellow) indicating the activation of TrkB by BDNF after TBS. Scale bars: $\boldsymbol{A}, 0.5 \mathrm{~mm}$; C, G, $0.05 \mathrm{~mm}$; D-J, $0.01 \mathrm{~mm}$. Error bars represent SEM.

tion of TrkB receptors in the RVM after inflammation contribute to the descending net facilitation and the induction and maintenance of behavioral hyperalgesia.

\section{Knockdown of endogenous TrkB receptors by RNAi attenuates hyperalgesia}

The involvement of TrkB activation in BDNF-dependent descending facilitation after inflammation was further demonstrated by RNAi methodology. We selectively knocked down endogenous TrkB receptor expression by introducing siRNA of TrkB receptors in the RVM to induce endogenous TrkB silencing by taking advantage of the electroporation technique in vivo (Wei et al., 2003; Akaneya et al., 2005). A single injection of TrkB siRNA (70 and $280 \mathrm{ng}$ ), control siRNA (70 ng), or vehicle (free RNAase water; $500 \mathrm{nl}$ ) was injected into the RVM of the adult rats after focal electroporation. To verify the efficiency of siRNA transfer, a control siRNA conjugated with fluorescein (70 ng/500 $\mathrm{nl} ; n=3$ ) was injected before electroporation. We found a wide expression of fluorescein in RVM neurons at $24 \mathrm{~h}$ after gene transfer (Fig. 5A, B). Next, we assessed the effects of TrkB RNAi on expression of TrkB protein in the RVM by Western blots. Compared with the naive rats and rats receiving control siRNAs, a significant reduction of TrkB proteins was found in the RVM at 1 and $4 \mathrm{~d}$ after the TrkB siRNA transfer (Fig. $5 C)(n=3-4$ per group). Electroporation alone did not induce changes in TrkB expression (Fig. 5C). There was a slight decrease in TrkB expression in the RVM after microinjection of TrkB siRNA without electroporation (Fig. 5C). Compared with the rat receiving

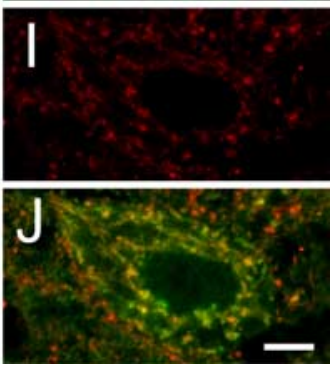

control siRNA (Fig. 5E), the TrkBimmunostaining was mostly reduced in the RVM at $4 \mathrm{~d}$ after transfer of TrkB siRNA (Fig. 5F). These results confirm successful TrkB siRNA transfer into RVM neurons and knockdown of TrkB expression.

Knockdown of TrkB receptor in the RVM by RNAi resulted in an attenuation of behavioral hyperalgesia after inflammation. Animals received a single transfer of TrkB siRNA into the RVM $4 \mathrm{~d}$ before hindpaw injection of CFA. The inflammation-induced enhancement of TrkB expression was blocked completely by TrkB RNAi but not control RNAi (Fig. 5D) at $1 \mathrm{~d}$ after CFA. The animals receiving siRNA $(10-280 \mathrm{ng}, n=4-6)$ exhibited a significant and dosedependent attenuation of thermal hyperalgesia from $30 \mathrm{~min}$ to $6 \mathrm{~h}$ after hindpaw injection of CFA, compared with the control siRNA-treated rats $(n=6)$ (Fig. $5 G$ ). There were no changes in basal paw withdrawal latency to noxious heat before and after siRNA transfer in rats before inflammation (Fig. $5 G$ ). These results are consistent with the BDNF neutralization experiments and indicate a role of TrkB activation in descending pain facilitation after inflammation.

\section{Exogenous BDNF induces facilitation of nociception through activation of NMDA receptors}

The above findings suggest that BDNF in brainstem descending pathways contributes to pain hypersensitivity after inflammation. To mimic BDNF-dependent descending facilitation after inflammation, naive rats received a single microinjection of BDNF (270 pg/500 nl, $100 \mathrm{fmol} ; n=6$ ) into the RVM. This dose of BDNF produced a significant decrease in paw withdrawal latency to a noxious thermal stimulus from 4 to $24 \mathrm{~h}$ after BDNF infusion, compared with rats treated with vehicle $(n=5)$ (Fig. $6 A$ ). A lower dose of BDNF (27 pg/500 nl, $10 \mathrm{fmol} ; n=6$ ) also produced a significant but shorter facilitation of thermal sensitivity only at the $4 \mathrm{~h}$ time point (Fig. $6 \mathrm{~A}$ ).

To determine whether the doses of BDNF were within the range of in vivo conditions, we first injected a $500 \mathrm{nl}$ volume of streptavidin-conjugated Alexa Fluor 568 (1:100) into the RVM to determine the amount of the tissues affected by microinjection. The fluorescence was found to diffuse into an area $\sim 2 \mathrm{~mm}^{2}$ surrounding the injection site, and the fluorescence-diffused tissues weighed $3.0 \pm 1.0 \mathrm{mg}(n=3)$. We then measured BDNF concentrations in the same volume of RVM tissue in naive and CFA-treated animals by using a conventional BDNF ELISA protocol. The concentration of BDNF was significantly increased from $46.2 \pm 1.4 \mathrm{pg} / \mathrm{mg}$ in naive animals $(n=4)$ to $67.9 \pm 7.1$ $\mathrm{pg} / \mathrm{mg}$ tissue at $24 \mathrm{~h}$ after inflammation $(n=4)(p<0.05)$ (Fig. $6 B)$, consistent with an enhanced release of BDNF in the RVM. Thus, the doses $(27-270$ pg or 10-100 fmol) that facilitated nociception (Fig. 6A) were within the physiological range.

It is well established that BDNF facilitates glutamatergic synaptic transmission and is involved in activity-dependent long- 

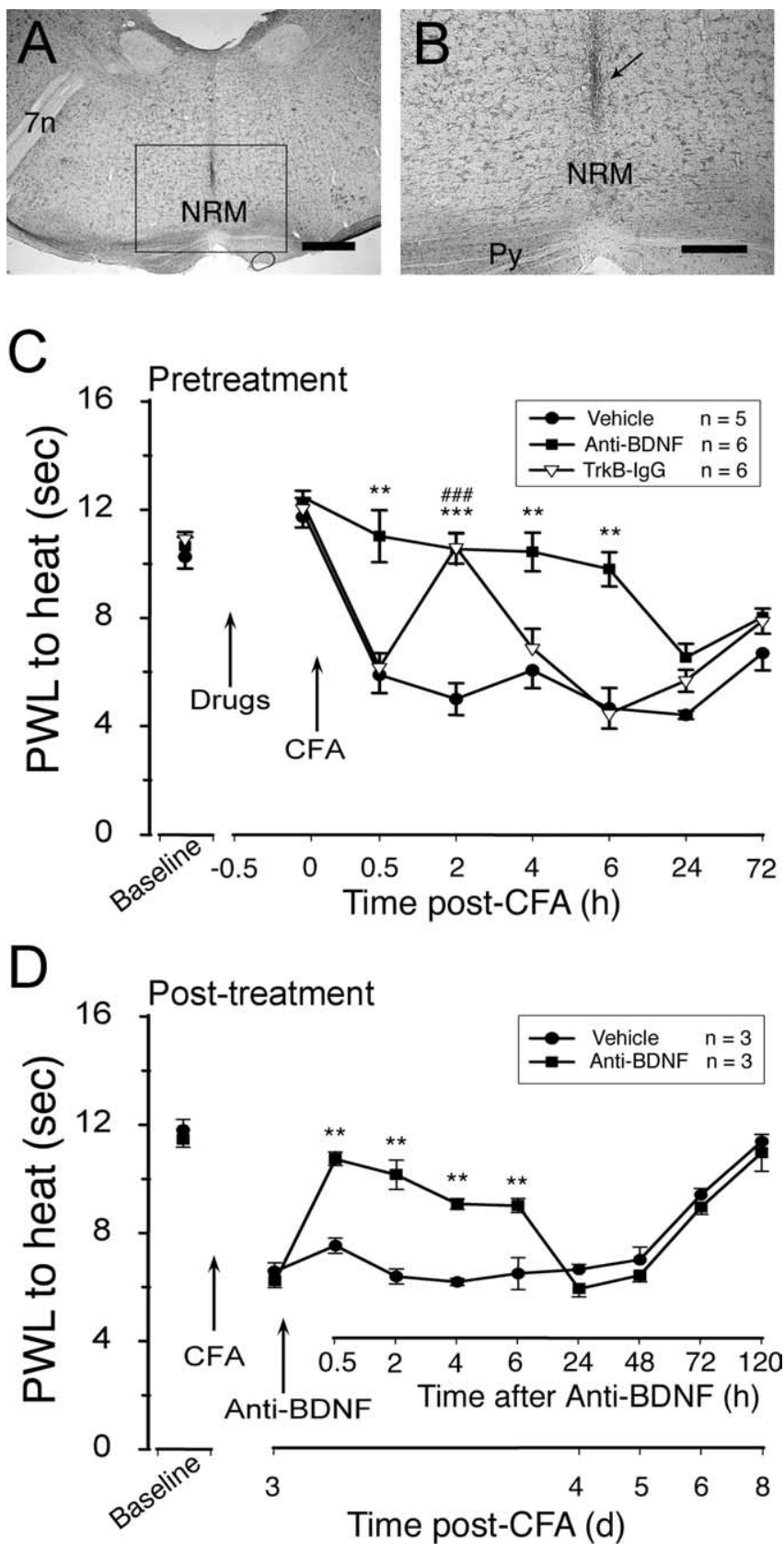

Figure 4. Neutralizing endogenous BDNF in the RVM attenuates inflammatory hyperalgesia. $\boldsymbol{A}, \boldsymbol{B}$, An example of Nissl-stained section showing the track ( $\boldsymbol{B}$, arrow) of intra-RVM microinjection. $\boldsymbol{B}$ is an enlarged image from the inset in $\boldsymbol{A}$. $7 \mathrm{n}$, Facial nerve; Py, pyramidal tract. Effects of intra-RVM anti-BDNF antisera or TrkB-IgG on inflammatory hyperalgesia are shown in $C$ and D. Thermal hyperalgesia was assessed by paw withdrawal latency (PWL) to a noxious heat stimulus, as indicated by a significant reduction of PWL. Anti-BDNF antisera $(25 \mathrm{ng} / 500 \mathrm{nl})$, TrkB-lgG $(50 \mathrm{ng} / 500 \mathrm{nl})$, or vehicle (saline) was microinjected into the RVM at $0.5 \mathrm{~h}$ before the injection of CFA. C, Compared with vehicle-injected rats, pretreatment with anti-BDNF significantly attenuated thermal hyperalgesia for at least $6 \mathrm{~h}$ (asterisks, $p<0.01-0.001$ ). Pretreatment with TrkB-lgG reversed the PWL to the pre-CFA level at $2 \mathrm{~h}$ after CFA ( $\left.{ }^{\# \# \#} p<0.001\right)$. D Posttreatment with anti-BDNF antisera also significantly attenuated behavioral hyperalgesia, compared with vehicle-treated rats $\left({ }^{* *} p<0.01\right)$.

term synaptic plasticity in the hippocampus and neocortex (Figurov et al., 1996; Levine et al., 1998; Schinder and Poo, 2000; Kovalchuk et al., 2004). We have shown that upregulation of NMDAR subunit expression occurred in the RVM after inflammation (Miki et al., 2002). Our double immunohistochemistry labeling indicated that TrkB colocalized with NR2A in RVM neu- rons (Fig. 6C). To test whether NMDARs contribute to BDNFinduced descending facilitation, we microinjected AP-5, an NMDAR antagonist into the RVM. Microinjection of AP-5 (10 pmol; $n=4$ ) alone did not affect baseline thermal nociceptive threshold (Fig. 6D). However, preadministration of AP-5 (10 pmol) abolished BDNF (100 fmol)-induced facilitation of the paw withdrawal response to noxious heat $(n=6$; $p<0.05)$ (Fig. $6 D)$. The pretreatment with $(+)-5$-methyl-10,11-dihydro- $5 \mathrm{H}$ dibenzo[a,d]cyclohepten-5,10-imine hydrogen maleate or dizocilpine maleate $(0.1 \mathrm{nmol})$, an NMDAR channel blocker, also abolished BDNF-produced facilitation (data not shown).

We next examined whether exogenous BDNF application activates NMDARs, as indicated by phosphorylation of the NMDAR subunit. RVM tissues were removed at $30 \mathrm{~min}$ after microinjection of BDNF ( $100 \mathrm{fmol} ; n=5)$ in vivo. Protein samples from RVM were first immunoprecipitated with anti-NR2A antibodies. The eluted NR2A proteins were subsequently analyzed by Western blot using 4G-10, a selective antiphosphotyrosine antibody. The level of NR2A tyrosine phosphorylation was significantly increased in BDNF-treated rats compared with the vehicle-injected rats (Fig. 6E). Additionally, there was a time-dependent increase in NR2A, but not NR2B (data not shown), tyrosine phosphorylation in the RVM after inflammation (Fig. 6 F). These results suggest that NMDARs mediate BDNF-induced descending facilitation.

\section{Cellular mechanisms for BDNF-induced NR2A tyrosine phosphorylation in the RVM}

Our results suggest an interaction between BDNF-TrkB signaling and NMDAR activation in the RVM after inflammation, which is consistent with the view that NMDAR is a downstream target of BDNF (Lin et al., 1998; Di Luca et al., 2001; Slack et al., 2004). Using an in vitro RVM slice preparation, we examined some key signal transduction steps involved in BDNF-induced NR2A phosphorylation. Transverse brainstem slices, including RVM, were obtained and treated with $\operatorname{BDNF}(18.5 \mathrm{nM})$ for $10 \mathrm{~min}$. Consistent with the in vivo experiment (Fig. 6E), bath application of BDNF induced a significant increase in NR2A tyrosine phosphorylation in the RVM $(n=6$; $p<0.05)$ (Fig. 7A). The increased NR2A tyrosine phosphorylation was blocked by pretreatment with an $\mathrm{IP}_{3}$ receptor antagonist 2-aminoethoxydiphenyl borate (2-APB) $(0.036 \mathrm{~mm} ; n=4 ; p<0.05)$ (Fig. $7 B)$, the PKC inhibitor chelerythrine $(0.01 \mathrm{~mm} ; n=4 ; p<0.05)$ (Fig. $7 C)$, and the Src family tyrosine kinase inhibitor 4-amino-5-(4-chlorophenyl)-7-( $t$-butyl)pyrazolo[3,4-d]pyrimidine (PP2) (0.04 mM; $n=4)$ (Fig. $7 D)$. These results identified a direct signaling role for $\mathrm{IP}_{3}, \mathrm{PKC}$, and $\mathrm{Src}$ in mediating BDNF-induced elevation of NR2A tyrosine phosphorylation in RVM neurons. In contrast, the group I metabotropic glutamate receptor (mGluR) antagonist 1-aminoindan-1,5-dicarboxylic acid (AIDA) did not have an effect on BDNF-induced phosphorylation of NR2A in the RVM (Fig. 7E), suggesting that different from spinal dorsal horn (Guo et al., 2004), BDNF-induced NR2A phosphorylation is not dependent on mGluR activation. It remains to be determined, however, whether other G-protein-coupled receptors such as NK1 tachykinin receptors mediate BDNF-induced NR2A phosphorylation in the RVM. The basal levels of NR2A tyrosine phosphorylation in RVM slices were not affected by bath application of 2-APB (0.036 mM), chelerythrine (0.01 mM), and PP2 (0.04 mM) $(n=3$ per drug; data not shown). 

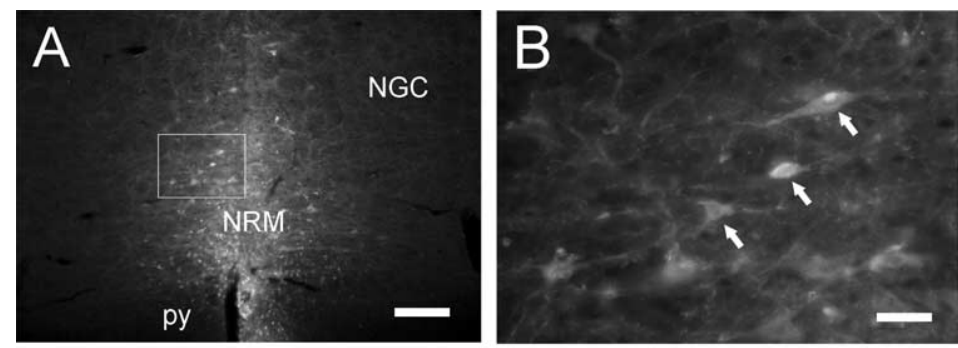

C

D
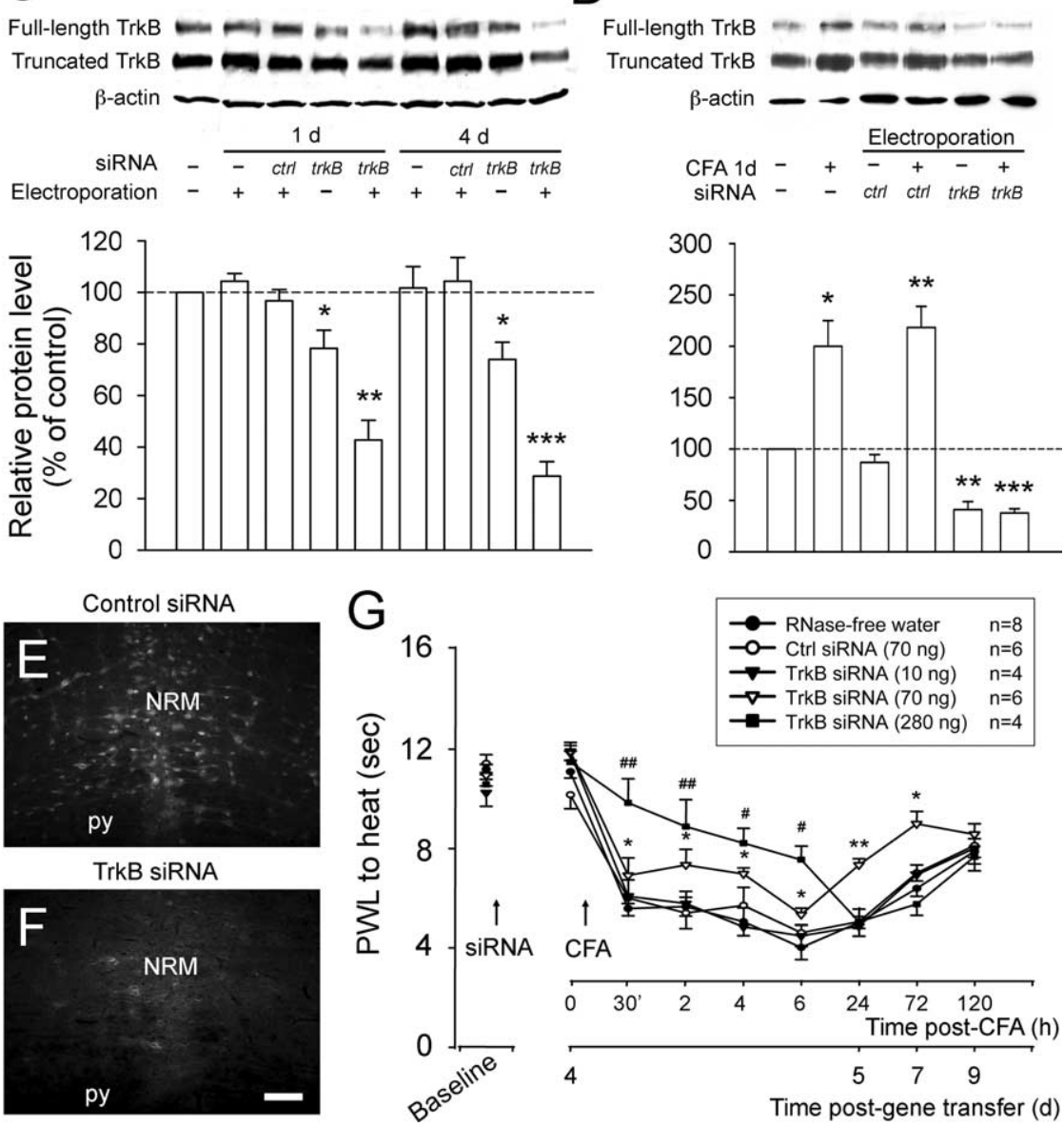

Figure 5. Knockdown of endogenous TrkB receptors by RNAi attenuates inflammatory hyperalgesia. $\boldsymbol{A}, \boldsymbol{B}$, Expression of fluorescein in RVM neurons at $24 \mathrm{~h}$ after electroporation transfer of a control siRNA conjugated with fluorescein $(70 \mathrm{ng} / 500 \mathrm{nl} ; n=$ 3). $\boldsymbol{B}$ is magnified from the inset in $\boldsymbol{A}$. Arrows in $\boldsymbol{B}$ indicate examples of fluorescein-expressing neurons. $\boldsymbol{C}$, Western blot analysis shows a significant reduction of TrkB proteins in the RVM at 1 and $4 \mathrm{~d}$ after the TrkB siRNA transfer ( $n=3-4 /$ per group). The top blots show examples of the immunoreactive bands against anti-TrkB that identifies both full-length and truncated TrkB. The bottom bar graph shows the mean levels of the full-length TrkB normalized to $\beta$-actin. The relative TrkB levels (mean \pm SEM) are expressed as a percentage of the control (first lane from the left) for the purpose of illustration. Raw data are used for statistical comparisons. Asterisks indicate significant differences $\left({ }^{*} p<0.05 ;{ }^{* *} p<0.01 ;{ }^{* * *} p<0.001\right)$ from the control. The dashed line indicates the control level. $\boldsymbol{D}$, The inflammation-induced enhancement of TrkB expression was blocked by TrkB siRNA but not control siRNA at $1 \mathrm{~d}$ after CFA. $\boldsymbol{E}, \boldsymbol{F}$, TrkB immunostaining in the RVM at $4 \mathrm{~d}$ after transfer of control siRNA $(\boldsymbol{E} ; 70 \mathrm{ng} ; n=4)$ or TrkB siRNA ( $\boldsymbol{F} ; 70 \mathrm{ng} ; n=4)$. Scale bar, $0.1 \mathrm{~mm}$. $\boldsymbol{G}$, The animals receiving TrkB siRNA exhibited a significant and dose-dependent attenuation of thermal hyperalgesia from 30 min to $6 \mathrm{~h}$ after hindpaw injection of CFA, compared with the control siRNA-treated rats $(n=6)$. RNAase-free water $(n=8)$ was used as a control for control siRNA. There were no significant changes in basal paw withdrawal latency to noxious heat before and after siRNA transfer in rats before inflammation. Ctrl, Control; NGC, gigantocellular reticular nucleus; PWL, paw withdrawal latency; Py, pyramidal tract. ${ }^{\# * *} p<0.05,{ }^{\#, * * *} p<0.01$ versus control siRNA. Error bars represent SEM.

High doses of BDNF induce descending inhibition and downregulation of TrkB receptors in the RVM It has been reported that exogenously applied BDNF into the PAG produces analgesia in rats (Siuciak et al., 1994; Frank et al., 1997). However, the amount of BDNF applied in previous studies was higher (12 $\mu \mathrm{g} / \mathrm{d}$ for $1-11 \mathrm{~d})$ and appears to be out of the physiological range (see above). Similar phenomena were observed when higher doses of BDNF (10300 pmol) were injected into the RVM. There were dose-dependent increases in paw withdrawal latencies to noxious heat $(p<0.01)$ (Fig. 8A), indicating that BDNF in higher pharmacological concentrations induces analgesia. We further identified that a single intra-RVM injection of BDNF at 300 pmol produced a remarkable decrease in full-length TrkB, which appeared as early as $30 \mathrm{~min}$ and lasted for at least $3 \mathrm{~d}$ after BDNF treatment (Fig. $8 \mathrm{~B}$ ). These data are consistent with previous observations in other systems (Frank et al., 1997) and suggest that higher doses of BDNF produce descending inhibition by downregulation of TrkB receptors in RVM neurons. Alternatively, high doses of BDNF may activate p75 neurotrophin receptor to produce synaptic inhibition (Woo et al., 2005).

\section{Discussion}

Here, we provided evidence that BDNFTrkB signaling within the brainstem descending pathways contributes to net descending facilitation and plays an important role in the development of pain hypersensitivity. Recent studies have provided considerable evidence on the critical role of centrifugal excitatory input on persistent pain conditions (Urban and Gebhart, 1999; Porreca et al., 2002; Ren and Dubner, 2002; Vanegas and Schaible 2004). The present findings represent a systematic effort to address its coupling to TrkB activation and enhanced phosphorylation of the NMDAR subunit. We identified a novel PAG-RVM BDNFergic facilitatory influence that is activated by peripheral tissue injury, evidenced by upregulation of $\mathrm{BDNF}$ and $\operatorname{TrkB}$ after inflammation, stimulation-produced BDNF release, and contribution to behavioral hyperalgesia. We further show that BDNFproduced facilitation of nociception is blocked by NMDAR antagonists, and BDNF-TrkB signaling leads to NMDAR activation that involves $\mathrm{IP}_{3}, \mathrm{PKC}$, and Srcinduced NR2A tyrosine phosphorylation. The role of BDNF in persistent pain has been implicated in previous studies (Mannion et al., 1999; Pezet et al. 2002a). BDNF mRNA and protein levels are upregulated in the spinal cord after inflammation, and sequestration of endogenous BDNF blocks inflammatory hypersensitivity (Mannion et al., 1999). However, previous analyses focused on BDNF released from primary afferent neurons (supplemental Fig. 1, available at www.jneurosci.org as supplemental material). A role of BDNF in supraspinal cir- 
cuitry in descending pain facilitation has not been demonstrated. Our findings emphasize dynamic changes in BDNF-TrkB signaling in descending pathways and subsequent enhancement of NMDARdependent excitatory transmission, thus providing evidence for a supraspinal BDNFergic contribution to the initiation and maintenance of inflammatory pain.

\section{Descending projection of BDNF- containing neurons in PAG and pain facilitation}

In addition to a well documented role in endogenous pain inhibition, it has become clear that brainstem descending pathways also facilitate pain transmission (Urban and Gebhart, 1999; Wei et al., 1999; Guan et al., 2002; Porreca et al., 2002; Ren and Dubner, 2002; Heinricher et al., 2004; Vanegas and Schaible 2004). The present study shows that a not yet described PAG efferent projection, primarily from ventrolateral PAG neurons, releases BDNF into the RVM, activates TrkB and its signaling cascade and contributes to descending facilitation. This pathway responds to peripheral inflammation as shown by relevant increases in BDNF in PAG and TrkB in RVM neurons. Sequestration of BDNF and RNAi of TrkB in the RVM suppressed inflammatory hyperalgesia, indicating the importance of supraspinal BDNF in the inflammatory pain process. Previous studies have shown that BDNF is released from primary afferents and plays a role in pain hypersensitivity at the spinal level (Mannion et al., 1999; Lever et al., 2001). The present results suggest that BDNF in supraspinal pathways is at least equally important in facilitating central sensitization and the development of persistent pain (supplemental Fig. 1, available at www.jneurosci.org as supplemental material).

The present study also analyzed the relative role of endogenous and exogenous BDNF in nociception. The results showed that BDNF at physiological concentrations facilitates paw withdrawal from noxious heat. In contrast, higher doses of BDNF produced analgesia, which is consistent with previous reports (Siuciak et al., 1994; Frank et al., 1997). Additional results suggest that the inhibition of the paw withdrawal response by higher doses of BDNF is likely a result of TrkB downregulation (Frank et al., 1997). The BDNF-produced facilitation appeared only at $4 \mathrm{~h}$ after infusion, suggesting the involvement of complex intermediate pathways. BDNF does not appear to be tonically active because intra-RVM microinjection of TrkB-IgG or antiBDNF antibody does not affect basal nociception in non-CFAtreated animals. Instead, BDNF contributes to injury-induced neu-
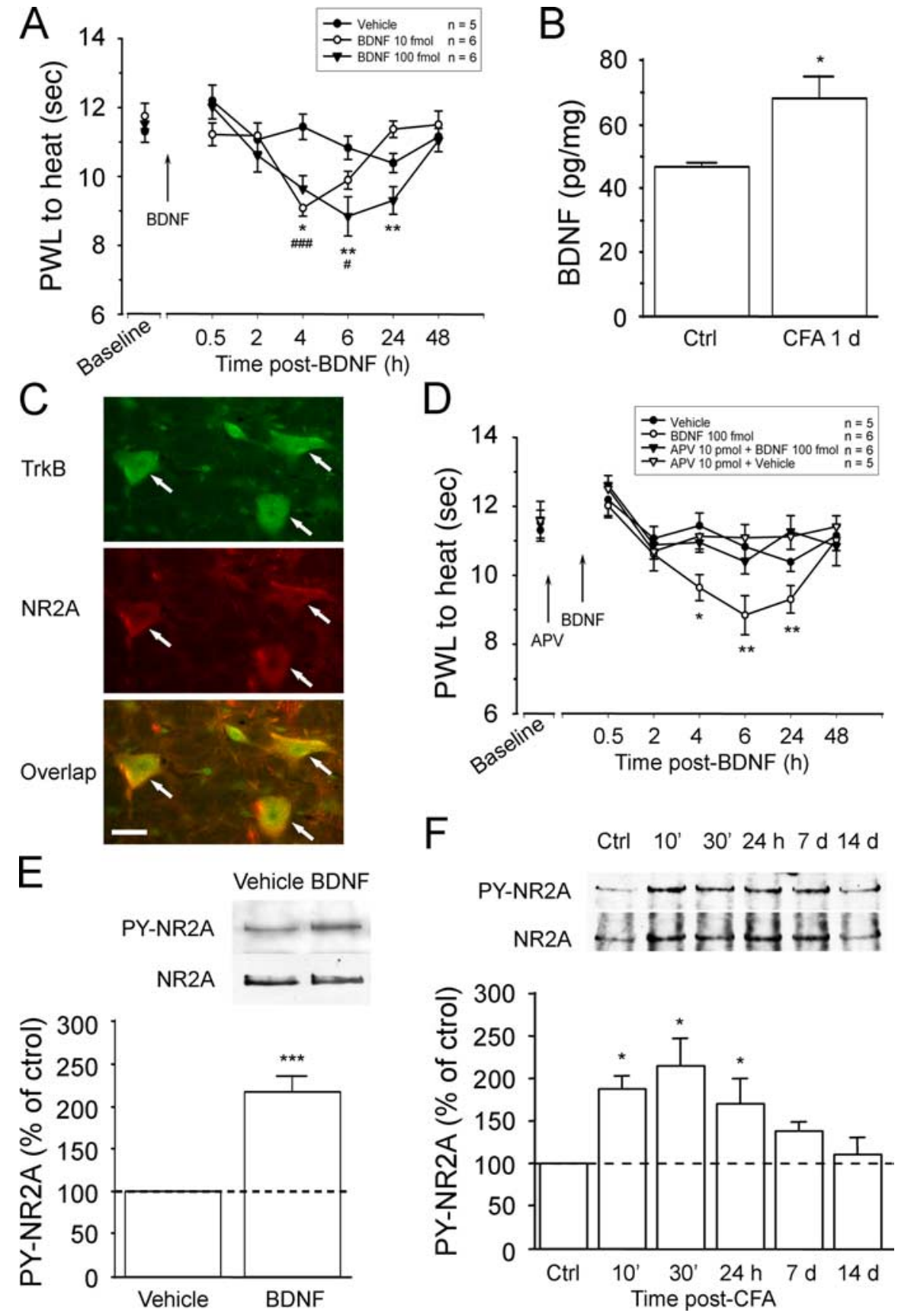

Figure 6. BDNF-produced facilitation of nociception through activation of NMDA receptors. $\boldsymbol{A}$, Low doses of intra-RVM BDNF treatment $(10-100 \mathrm{fmol})$ facilitated the nocifensive response to noxious heat stimulation, as indicated by a significant reduction in PWLs (10 fmol, $\left.{ }^{\#} p<0.05,{ }^{\# \# \#} p<0.001 ; 100 \mathrm{fmol},{ }^{*} p<0.05,{ }^{* *} p<0.01\right) . \boldsymbol{B}$, The levels of BDNF in the RVM tissue were measured by ELISA, which showed a significant increase at $24 \mathrm{~h}$ after CFA injection ( $p<0.05$ ). C, Colocalization of TrkB with NR2A subunit of the NMDAR in RVM neurons (arrows). Scale bar, $0.025 \mathrm{~mm}$. D, The BDNF-produced facilitation of PWLs was blocked by the pretreatment with the NMDAR antagonist AP-5 (10 pmol). $\boldsymbol{E}$, Microinjection of BDNF ( $100 \mathrm{fmol}$ ) into the RVM produced an increase in NR2A tyrosine phosphorylation $(p<0.001)$. $\boldsymbol{F}$, Western blot illustrating a significant increase in NR2A tyrosine phosphorylation in the RVM from 10 min to $24 \mathrm{~h}$ after CFA-induced inflammation ( $p<0.05 ; n=5$ ). Ctrl, Control; PWL, paw withdrawal latency; PY, pyramidal tract. Error bars represent SEM.

ronal plasticity. The BDNF-TrkB signaling is activated after inflammation to facilitate the generation and maintenance of inflammatory hyperalgesia. These findings suggest that application of BDNF for recovery from CNS injury and some mood disorders (Pezet and Malcangio, 2004) could lead to undesirable central pain. 


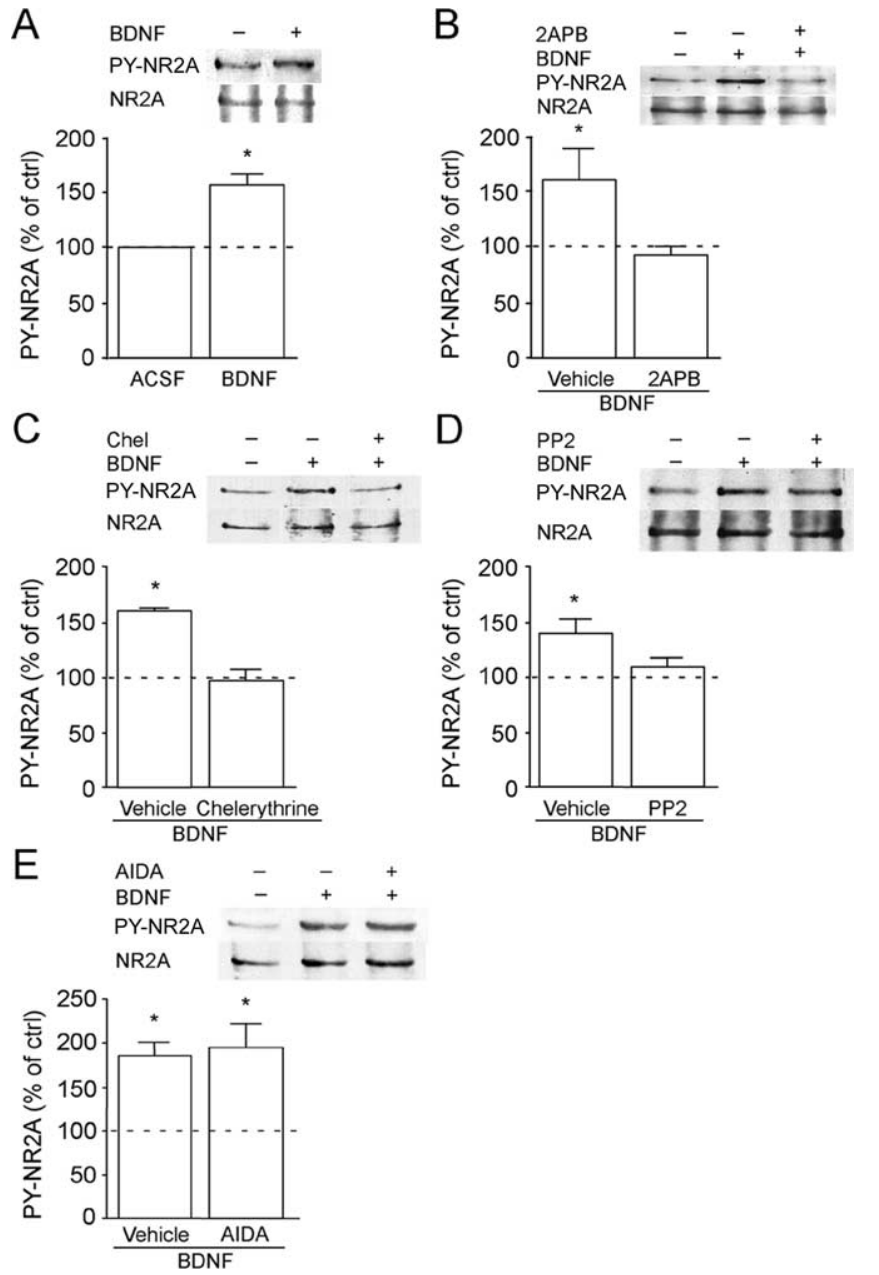

Figure 7. BDNF-induced NR2A tyrosine phosphorylation in vitro. The transverse brainstem slice including RVM was obtained from adult 8- to 10-week-old rats. The slices were incubated with BDNF (18.5 nM) for 10 min before protein extraction. In all panels, representative immunoblots against anti-4G-10 (PY-NR2A) and anti-NR2A antibodies are shown at the top, and mean relative levels of tyrosine-phosphorylated NR2A proteins are shown in the bar graphs. ${ }^{*} p<0.05$ versus untreated or vehicle-treated rats. $A$, BDNF induced a significant increase in PY-NR2A in the RVM slice. $\boldsymbol{B}-\boldsymbol{E}$, Pretreatment with an $\mathbb{I P}_{3}$ receptor antagonists 2-aminoethoxydiphenyl borate (2-APB; $0.036 \mathrm{~mm} ; n=4 ; \boldsymbol{B})$, a PKC inhibitor chelerythrine $(0.01 \mathrm{~mm} ; n=4 ; \boldsymbol{C})$, a Src family tyrosine kinase inhibitor PP2 (0.04 mм; $n=4 ; \boldsymbol{D})$, but not a group I metabotropic glutamate receptor (mGluR) antagonist, AIDA ( $0.3 \mathrm{~mm} ; n=4 ; \boldsymbol{E})$, blocked the BDNF-induced increase in PY-NR2A in the RVM. Ctrl, Control; PY, pyramidal tract. Error bars represent SEM.

\section{Dynamic BDNF-TrkB signaling and NMDA receptor activation after inflammation}

Previous studies have shown that neuronal plasticity induced by tissue injury within the brainstem pain modulatory circuitry involves an enhanced expression and activation of NMDAR in the RVM (Guan et al., 2002; Miki et al., 2002). The present study shows a time-dependent increase in NMDAR NR2A subunit tyrosine phosphorylation in the RVM after inflammation. What are the mechanisms of NMDAR-related plasticity within the RVM? There is increasing evidence that BDNF increases NMDAR function and open channel probability via a postsynaptic interaction between TrkB and NR2B in the hippocampus (Levine et al., 1998; Levine and Kolb, 2000). Recent studies have shown that BDNF enhanced phosphorylation of NMDAR subunits in the hippocampus (Lin et al., 1998) and spinal dorsal horn (Di Luca et al., 2001; Slack et al., 2004). Together with distinct

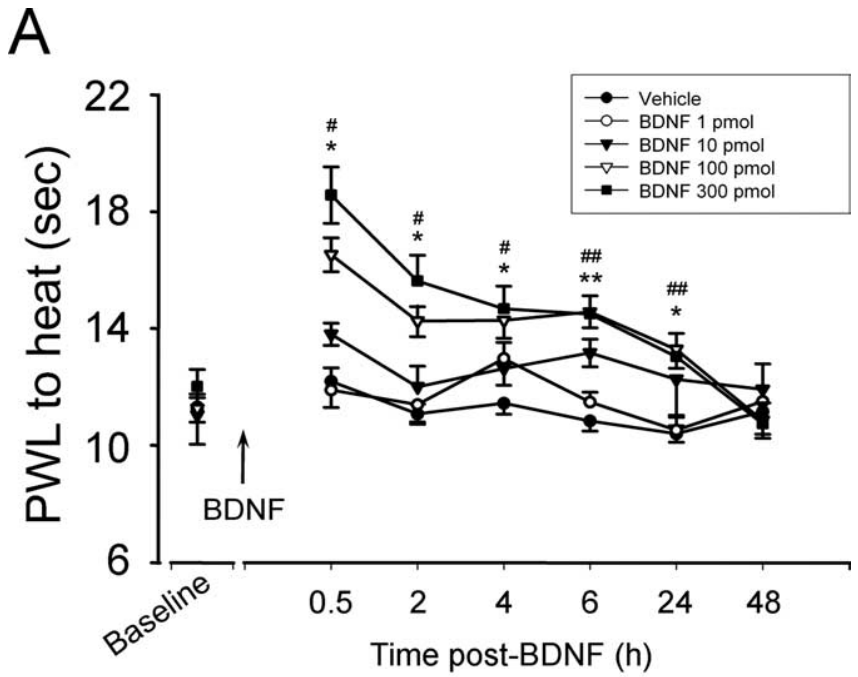

B

\section{Full-length TrkB Truncated TrkB}

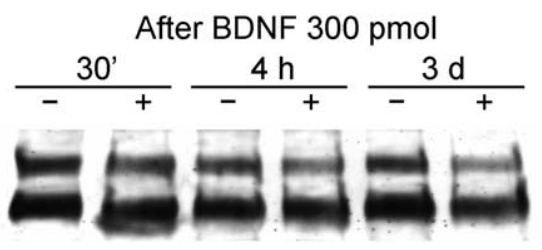

$\beta$-actin

Figure 8. High doses of BDNF induce descending inhibition and downregulation of the TrkB receptor $A, B D N F$ treatment at high doses (10-300 pmol) induced a significant elevation of paw withdrawal latencies (PWL) compared with vehicle-treated rats. ( $n=4-6$ per group). $\boldsymbol{B}$, Western blot analysis performed with anti-TrkB antibody on the RVM tissue extracts from $B D N F$ - or vehicle-treated rats. A reduced expression of full-length TrkB in the RVM was seen at $30 \mathrm{~min}, 4 \mathrm{~h}$, and $3 \mathrm{~d}$ after BDNF treatment.

distribution of BDNF-containing neurons in the PAG and expression of TrkB in spinally projection neurons in the RVM (Conner et al., 1997; Yan et al., 1997a,b; King et al., 1999), our results suggest an involvement of BDNF in NMDAR-dependent neuronal plasticity in enhanced descending modulation during inflammatory pain. Hindpaw inflammation upregulates BDNF proteins in the ventrolateral PAG, which is associated with an increase in BDNF and TrkB in the RVM. Importantly, there is an increased TrkB activation as shown by the increased TrkB phosphorylation. Behavioral studies demonstrate that NMDAR antagonists are able to block BDNF-induced nociceptive facilitation, suggesting that the effect of BDNF depends on downstream NMDAR activation. Two alternative mechanisms may underlie the action of BDNF after microinjection in the brain (Lessmann, 1998). First, BDNF may enhance glutamate release from presynaptic terminals in the RVM, leading to an increase in intracellular $\mathrm{Ca}^{2+}$ concentration through the activation of NMDARs, resulting in enhanced excitatory (facilitatory) descending output. Alternatively, BDNF may bind to postsynaptic TrkB receptors and enhance NMDAR activity through intermediate cellular signaling pathways (Pezet et al., 2002b). Our results demonstrate the latter mechanism because of the following: (1) activation of PAG neurons induced internalized and phosphorylated TrkB in RVM neurons and direct knockdown of TrkB expression in the RVM attenuated inflammatory hyperalgesia, and (2) BDNF is coupled to NMDAR activation.

BDNF-TrkB signaling activates several distinct cellular path- 
ways (Pezet et al., 2002a; Huang and Reichardt, 2003). The present results indicate that $\mathrm{IP}_{3}$ and $\mathrm{PKC}$ are involved in BDNFinduced and Src-mediated NR2A tyrosine phosphorylation in RVM neurons. Thus, this signaling pathway is likely initiated through phosphorylation of the tyrosine residue on TrkB that is related to activation of phospholipase C (Pezet et al., 2002a), which is followed by $\mathrm{IP}_{3}$ and diacylglycerol formation, intracellular calcium release, and PKC activation. These events may lead to Pyk2 (proline-rich tyrosine kinase 2) and Src activation and NR2A tyrosine phosphorylation (Huang et al., 2001; Guo et al., 2004). Distinct features are noticed for inflammation-induced NR2 tyrosine phosphorylation in the RVM when compared with the spinal dorsal horn. First, the NR2A subunit, but not the NR2B subunit, is tyrosine phosphorylated by BDNF. This is likely related to the differential distribution of the two subunits in the brain (Wenzel et al., 1995). Second, the group I mGluRs do not appear to play a role in BDNF-induced NR2A phosphorylation, suggesting different signaling pathways (Guo et al., 2004). It is yet to be determined whether serotoninergic neurons in the RVM also participate in BDNF-produced descending pain facilitation (Siuciak et al., 1998).

The present results indicate that supraspinal BDNF-TrkB signaling represents a novel molecular mechanism for descending facilitation of inflammatory pain. In addition to BDNF released from primary afferent terminals in the spinal cord, the supraspinal BDNFergic transmission may play an equally important role in initiating and maintaining spinal hyperexcitability after injury. Sequestering BDNF in the RVM reversed behavioral hyperalgesia, suggesting that supraspinal BDNF is necessary, if not sufficient, for inflammatory pain. These results reemphasize the importance of descending mechanisms in pain facilitation. The findings may also be generalized to other models of persistent pain as well as synaptic plasticity in CNS pathways. It also cautions that application of BDNF for recovery from CNS injury and some mood disorders could lead to undesirable central pain.

\section{References}

Akaneya Y, Jiang B, Tsumoto T (2005) RNAi-induced gene silencing by local electroporation in targeting brain region. J Neurophysiol 93:594-602.

Ceccatelli S, Ernfors P, Villar MJ, Persson H, Hökfelt T (1991) Expended distribution of mRNA for nerve growth factor, brain-derived neurotrophic factor, and neurotrophin 3 in the rat brain after colchicines treatment. Proc Natl Acad Sci USA 88:10352-10356.

Conner JM, Lauterborn JC, Yan Q, Gall CM, Varon S (1997) Distribution of brain-derived neurotrophic factor (BDNF) protein and mRNA in the normal adult rat CNS: evidence for anterograde axonal transport. J Neurosci 17:2295-2313.

Cui M, Feng Y, McAdoo DJ, Willis WD (1999) Periaqueductal gray stimulation-induced inhibition of nociceptive dorsal horn neurons in rats is associated with the release of norepinephrine, serotonin, and amino acids. J Pharmacol Exp Ther 289:868-876.

Di Luca M, Gardoni F, Finardi A, Pagliardini S, Cattabeni F, Battaglia G, Missale C (2001) NMDA receptor subunits are phosphorylated by activation of neurotrophin receptors in PSD of rat spinal cord. NeuroReport 12:1301-1305.

DiStefano PS, Friedman B, Radziejewski C, Alexander C, Boland P, Schick CM, Lindsay RM, Wiegand SJ (1992) The neurotrophins BDNF, NT-3, and NGF display distinct patterns of retrograde axonal transport in peripheral and central neurons. Neuron 8:983-993.

Du J, Feng L, Zaitsev E, Je HS, Liu XW, Lu B (2003) Regulation of TrkB receptor tyrosine kinase and its internalization by neuronal activity and $\mathrm{Ca}^{2+}$ influx. J Cell Biol 163:385-395.

Fields HL, Basbaum AI (1999) Central nervous system mechanisms of pain modulation. In: Textbook of pain (Wall PD, Melzack R, eds), pp 309-329. Edinburgh: Churchill Livingstone.

Figurov A, Pozzo-Miller LD, Olafsson P, Wang T, Lu B (1996) Regulation of synaptic responses to high-frequency stimulation and LTP by neurotrophins in the hippocampus. Nature 381:706-709.

Frank L, Wiegand SJ, Siuciak JA, Lindsay RM, Rudge JS (1997) Effects of BDNF infusion on regulation of TrkB protein and message in adult rat brain. Exp Neurol 145:62-70.

Guan Y, Terayama R, Dubner R, Ren K (2002) Plasticity in excitatory amino acid receptor-mediated descending pain modulation after inflammation. J Pharmacol Exp Ther 300:513-520.

Guan Y, Guo W, Zou S-P, Dubner R, Ren K (2003) Inflammation-induced upregulation of AMPA receptor subunit expression in brain stem pain modulatory circuitry. Pain 104:401-413.

Guo W, Wei F, Zou S, Robbins MT, Sugiyo S, Ikeda T, Tu JC, Worley PF, Dubner R, Ren K (2004) Group I metabotropic glutamate receptor NMDA receptor coupling and signaling cascade mediate spinal dorsal horn NMDA receptor 2B tyrosine phosphorylation associated with inflammatory hyperalgesia. J Neurosci 24:9161-9173.

Hargreaves K, Dubner R, Brown F, Flores C, Joris J (1988) A new and sensitive method for measuring thermal nociception in cutaneous hyperalgesia. Pain 32:77-88.

Heinricher MM, Martenson ME, Neubert MJ (2004) Prostaglandin E2 in the midbrain periaqueductal gray produces hyperalgesia and activates pain-modulating circuitry in the rostral ventromedial medulla. Pain 110:419-426.

Huang EJ, Reichardt LF (2003) Trk receptors: roles in neuronal signal transduction. Annu Rev Biochem 72:609-642.

Huang Y, Lu W, Ali DW, Pelkey KA, Pitcher GM, Lu YM, Aoto H, Roder JC, Sasaki T, Salter MW, MacDonald JF (2001) CAKbeta/Pyk2 kinase is a signaling link for induction of long-term potentiation in CA1 hippocampus. Neuron 29:485-496.

Iadarola MJ, Brady LS, Draisci G, Dubner R (1988) Enhancement of dynorphin gene expression in spinal cord following experimental inflammation: stimulus specificity, behavioral parameters and opioid receptor binding. Pain 35:313-326.

Kerr BJ, Bradbury EJ, Bennett DL, Trivedi PM, Dassan P, French J, Shelton DB, McMahon SB, Thompson SW (1999) Brain-derived neurotrophic factor modulates nociceptive sensory inputs and NMDA-evoked responses in the rat spinal cord. J Neurosci 19:5138-5148.

King VR, Michael J, Joshi RK, Priestley JV (1999) TrkA, TrkB, and TrkC messenger RNA expression by bulbospinal cells of the rat. Neuroscience 92:935-944.

Kovalchuk Y, Holthoff K, Konnerth A (2004) Neurotrophin action on a rapid timescale. Curr Opin Neurobiol 14:558-563.

Lessmann V (1998) Neurotrophin-dependent modulation of glutamatergic synaptic transmission in the mammalian CNS. Gen Pharmacol 31:667-674.

Lever I, Bradbury EJ, Cunningham JR, Adelson DW, Jones MG, McMahon SB, Marvizon JC, Malcangio M (2001) Brain-derived neurotrophic factor is released in the dorsal horn by distinctive patterns of afferent fiber stimulation. J Neurosci 21:4469-4477.

Levine ES, Kolb JE (2000) Brain-derived neurotrophic factor increases activity of NR2B-containing $N$-methyl-D-aspartate receptors in excised patches from hippocampal neurons. J Neurosci Res 62:357-362.

Levine ES, Corzier RA, Black IB, Plummer M (1998) BDNF modulates hippocampal synaptic transmission by increasing $N$-methyl-D-aspartic acid receptor activity. Proc Natl Acad Sci USA 95:10235-10239.

Lin S-Y, Wu K, Levine ES, Mount HT, Suen PC, Black IB (1998) BDNF acutely increases tyrosine phosphorylation of the NDMA receptor subunit $2 \mathrm{~B}$ in cortical and hippocampal postsynaptic densities. Mol Brain Res $55: 20-27$

Lu B (2003) BDNF and activity-dependent synaptic modulation. Learn Mem 10:86-98.

Malcangio M, Lessmann V (2003) A common thread for pain and memory synapses? Brain-derived neurotrophic factor and trkB receptor. Trends Pharmacol Sci 24:116-121.

Mannion RJ, Costigan M, Decosterd I, Amaya F, Ma QP, Holstege JC, Ji RR, Acheson A, Lindsay RM, Wilkinson GA, Woolf CJ (1999) Neurotrophins: peripherally and centrally acting modulators of tactile stimulusinduced inflammatory pain hypersensitivity. Proc Natl Acad Sci USA 96:9385-9390.

Miki K, Zhou Q, Guo W, Guan Y, Terayama R, Dubner R, Ren K (2002) Changes in gene expression and neuronal phenotype in brainstem pain modulatory circuitry after inflammation. J Neurophysiol 87:750-760. 
Paxinos G, Watson C (2005) The rat brain in stereotaxic coordinates, Ed 5. Amsterdam: Elsevier.

Pezet S, Malcangio M (2004) Brain-derived neurotrophic factor as a drug target for CNS disorders. Expert Opin Ther Targets 8:391-399.

Pezet S, Malcangio M, McMahon SB (2002a) BDNF: a neuromodulator in nociceptive pathways? Brain Res Brain Res Rev 40:240-249.

Pezet S, Malcangio M, Lever IJ, Perkinton MS, Thompson SW, Williams RJ, McMahon SB (2002b) Noxious stimulation induces Trk receptor and downstream ERK phosphorylation in spinal dorsal horn. Mol Cell Neurosci 21:684-695.

Porreca F, Ossipov M, Gebhart GF (2002) Chronic pain and medullary descending facilitation. Trends Neurosci 25:319-325.

Ren K, Dubner R (2002) Descending modulation in persistent pain: an update. Pain 100:1-6.

Schinder AF, Poo MM (2000) The neurotrophin hypothesis for synaptic plasticity. Trends Neurosci 23:639-645.

Siuciak JA, Alter CA, Wiengand SJ, Lindsay RM (1994) Antinociceptive effect of brain-derived neurotrophic factor and neurotrophin-3. Brain Res 633:326-330.

Siuciak JA, Clark MS, Rind HB, Whittemore SR, Russo AF (1998) BDNF induction of tryptophan hydroxylase mRNA levels in the rat brain. J Neurosci Res 52:149-158.

Slack SE, Pezet S, McMahon SB, Thompson SW, Malcangio M (2004) Brain-derived neurotrophic factor induces NMDA receptor subunit one phosphorylation via ERK and PKC in the rat spinal cord. Eur J Neurosci 20:1769-1778.

Urban M, Gebhart GF (1999) Supraspinal contributions to hyperalgesia. Proc Natl Acad Sci USA 69:7687-7692.

Van Bockstaele EJ, Aston-Jones G, Pieribone VA, Ennis M, Shipley MT
(1991) Subregions of the periaqueductal gray topographically innervate the rostral ventral medulla in the rat. J Comp Neurol 309:305-327.

Vanegas H, Schaible H-G (2004) Descending control of persistent pain: inhibitory or facilitatory? Brain Res Brain Res Rev 46:295-309.

Wei F, Dubner R, Ren K (1999) Nucleus reticularis gigantocellularis and nucleus raphe magnus in the brain stem exert opposite effects on behavioral hyperalgesia and spinal Fos protein expression after peripheral inflammation. Pain 80:127-141.

Wei F, Qiu CS, Liauw J, Robinson DA, Ho N, Chatila T, Zhuo M (2002) Calcium calmodulin-dependent protein kinase IV is required for fear memory. Nat Neurosci 5:573-579.

Wei F, Xia XM, Tang J, Ao H, Ko S, Liauw J, Qiu CS, Zhuo M (2003) Calmodulin regulates synaptic plasticity in the anterior cingulate cortex and behavioral responses: a microelectroporation study in adult rodents. J Neurosci 23:8402-8409.

Wenzel A, Scheurer L, Kunzi R, Fritschy JM, Mohler H, Benke D (1995) Distribution of NMDA receptor subunit proteins NR2A, 2B, 2C and 2D in rat brain. NeuroReport 7:45-48.

Woo NH, Teng HK, Siao CJ, Chiaruttini C, Pang PT, Milner TA, Hempstead BL, Lu B (2005) Activation of p75NTR by proBDNF facilitates hippocampal long-term depression. Nat Neurosci 8:1069-1077.

Yan Q, Rosenfeld RD, Matheson CR, Hawkins N, Lopez OT, Bennett L, Welcher AA (1997a) Expression of brain-derived neurotrophic factor (BDNF) protein in the adult rat central nervous system. Neuroscience 78:431-448.

Yan Q, Radeke MJ, Matheson CR, Talvenheimo J, Welcher AA, Feinstein SC (1997b) Immunocytochemical localization of TrkB in the central nervous system of the adult rat. J Comp Neurol 378:135-157. 